\title{
GAIA Level 1 Major Functional Defect
}

National Cancer Institute

\section{Source}

National Cancer Institute. GAIA Level 1 Major Functional Defect. NCI Thesaurus. Code C127965.

GAIA Level 1 Major Functional Defect is defined by two criteria. first, at least one of the following requirements must be met: a) For live births, there must be alterations in functioning of one or more organs or body parts that are not due to a structural defect, that are present at the time of birth (or propensity to develop alteration present at live birth), and that persist beyond the immediate peripartum period unless treated through gene therapy or stem cell transplantation; OR b) For stillbirths or for spontaneous or therapeutic abortions, there must be alterations in the function of one or more organs or body parts that are not due to a structural defect; second, there must be confirmation of the defect(s) by definitive diagnostic study. 